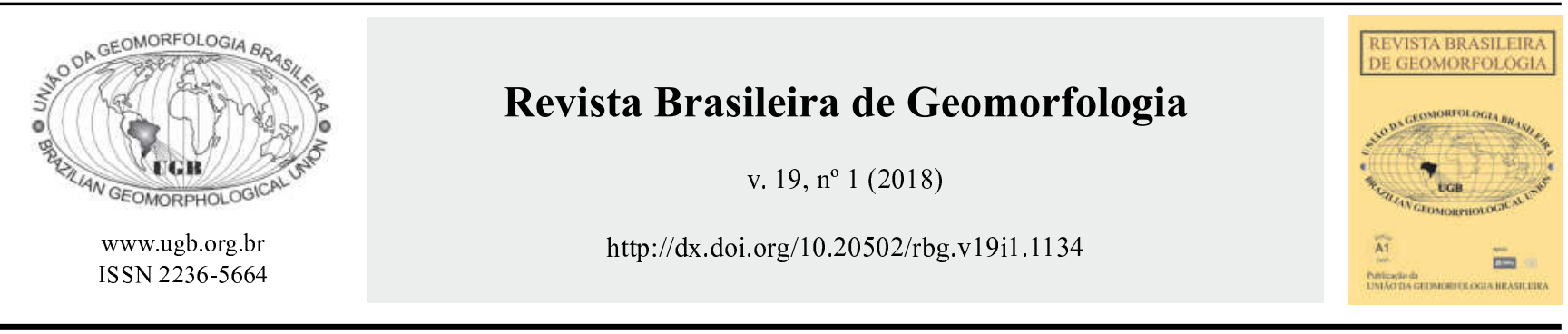

\title{
CARACTERIZAÇÃO DE ATRIBUTOS DO SOLO DE TRILHAS ECOTURÍSTICAS EM UNIDADES DE CONSERVAÇÃO DO MUNICÍPIO DE PARATY (RJ)
}

\section{CHARACTERIZATION OF SOIL ATTRIBUTES IN ECOTURISTIC TRAILS IN PROTECTED AREAS IN PARATY MUNICIPALITY (RJ)}

\author{
Luana de Almeida Rangel \\ Departamento de Geografia, Universidade Federal do Rio de Janeiro \\ Av. Athos da Silveira Ramos, 274, Rio de Janeiro, Rio de Janeiro, CEP 21940- 590, Brasil
}

Email: luarangel@ufrj.br

Antonio Jose Teixeira Guerra

Departamento de Geografia, Universidade Federal do Rio de Janeiro Av. Athos da Silveira Ramos, 274, Rio de Janeiro, Rio de Janeiro, CEP 21940- 590, Brasil

Email: antoniotguerra@gmail.com

\section{Informações sobre o Artigo \\ Recebido (Received): \\ $12 / 03 / 2017$ \\ Aceito (Accepted): \\ 20/09/2017}

\section{Palavras-chave:}

Erosão dos Solos; Propriedades Físico-Químicas; Ecoturismo.

\section{Keywords:}

Soil Erosion; Soil

Physicochemical Properties; Ecotourism.

\begin{abstract}
Resumo:
Em áreas tropicais úmidas, a erosão hídrica é a grande responsável pela perda de solo. A análise de atributos do solo permite inferir áreas que estão sofrendo com processos erosivos e outros tipos de degradação. A atividade ecoturística, pode ser uma forma de conservação do ambiente natural. Porém, a utilização de trilhas pode acarretar impactos quando não há planejamento e manejo adequados para implementação e utilização. A presente pesquisa analisou propriedades do solo, mapeando a ocorrência de processos erosivos em duas trilhas ecoturísticas localizadas no litoral de duas Unidade de Conservação no município de Paraty (RJ), a Reserva Ecológica da Juatinga (REJ) e o Parque Nacional da Serra da Bocaina (PNSB). Foram coletadas amostras de solo em dois pontos em cada trilha para avaliar propriedades químicas e físicas como textura, densidade, porosidade, matéria orgânica e $\mathrm{pH}$; foram mapeadas feições erosivas e degradações; e, foi estabelecido o grau de dificuldade nas trilhas. Constata-se que a maioria das feições erosivas mapeadas surgiu a partir da implementação das trilhas, já que o traçado delas não é curvilíneo. A retirada da vegetação e a declividade foram fatores determinantes para o surgimento de ravinas e erosão da borda principalmente na trilha localizada na REJ. O efeito do pisoteio evidenciou-se a partir da densidade crítica do solo $\left(1,4-1,5 \mathrm{~g} / \mathrm{cm}^{3}\right)$. A grande concentração de partículas finas (areia fina + silte superior a $45 \%$ ) também foi determinante para que fossem atribuídos grau de dificuldade médio, na trilha do PNSB, e elevado, na trilha da REJ.
\end{abstract}

\footnotetext{
Abstract:

In tropical areas, water erosion stands as largely responsible for the soil loss. The analysis of soil attributes allows inferring areas that are suffering from
} 
erosion and other types of degradation. The ecotourism activity, can be a form of conservation of the natural environment. However, the use of trails can cause impacts when there is no planning and management suitable for implementation and use. This research work examined the soil properties, mapping the occurrence of erosion in two ecotourism trails located on the coast of two protected areas in Paraty Municipality Rio de Janeiro State, the Juatinga Ecological Reserve (JER) and the Serra da Bocaina National Park (SBNP). Soil samples were collected at four sites (two on each trail) to assess physical and chemical properties as soil texture, density, porosity, organic matter and $\mathrm{pH}$; erosional features and degradation features were mapped; and it has established the degree of difficulty on the trails. It was found that most of the mapped erosional features came from the implementation of the trails, since their layout is not curved. Vegetation clearance and slope angle were determining factors for the occurrence of rills and erosion on the borders mainly on the trail located in the ERJ. The effect of trampling was evident from the critical soil density $\left(1.4-1.5 \mathrm{~g} / \mathrm{cm}^{3}\right.$ ). The high concentration of fine particles (sand + silt more than $45 \%$ ) was also a determining factor to be assigned average degree of difficulty, on the SBNP trail, and high, on the JER trail.

\section{Introdução}

A degradação dos solos está diretamente relacionada a processos complexos que incluem a erosão (hídrica e/ou eólica), a desertificação, os movimentos de massa, a salinização e a acidificação (FULLEN; CATT, 2004; ARAÚJO et al., 2013). Dentro desses processos, a erosão hídrica se destaca como a maior responsável pela perda de solo. Morgan (2005) destaca que os processos de formação dos solos são afetados diretamente pelos processos erosivos, prejudicando, assim, a renovação desse recurso.

Wild (1993) destaca que os principais fatores que influenciam à erosão são o desmatamento, a construção e o manejo inadequado de rodovias que provoca impermeabilização do solo, o desenvolvimento da agricultura e pecuária sem adoção de práticas conservacionistas e realizadas em encostas com elevada declividade, trilhas abertas por homens e animais que geram a compactação do solo, e atividades econômicas que deixam o solo desprotegido, como a mineração sem adequação às leis ambientais.

Segundo Bertoni e Lombardi Neto (2010), a erosão hídrica é a forma mais ativa de degradação dos solos, principalmente nos climas úmidos, sendo um processo natural influenciado por diversos fatores como a chuva, o solo, a topografia, a cobertura vegetal, o manejo e pelas práticas conservacionistas. Entre esses fatores é possível destacar o tipo de cobertura vegetal e o manejo do solo como os principais agentes no desenvolvimento de processos erosivos (GUADAGNIN et al., 2005).

Sobre a influência da cobertura vegetal nos processos de erosão, Gyssels et al. (2005) ressaltam que a vegetação pode controlar a erosão do solo, por meio da interceptação - através da densidade de sua copa, raízes, e folhas - alterando a distribuição do tamanho das gotas de chuva e controlando o escoamento superficial. Portanto, há necessidade de se conservar áreas de fragilidade ambiental. De acordo com Ross (1994), as características genéticas dos ambientes naturais podem conferir fragilidade caso ocorra uma intervenção antrópica. Além disso, o autor destaca que os ambientes naturais se encontravam em equilíbrio dinâmico até o início progressivo das intervenções humanas na exploração de recursos naturais. Neste sentido, essas intervenções alteram a qualidade ambiental, sendo necessária a delimitação de áreas prioritárias para conservação. Para isso, a criação de Unidades de Conservação e o incentivo às atividades de baixo impacto ambiental sob esses ambientes se tornaram extremamente relevantes.

O ecoturismo é uma vertente da atividade turística que possui baixo impacto ambiental e segundo Irving (2008) é um fenômeno social que proporciona uma experiência de valor afetivo com o meio natural e cultural, tendo a natureza protegida como atrativo principal.

Atualmente, o ecoturismo é o segmento da atividade turística que apresenta o elevado crescimento no Brasil (KROEFF, 2010; EMBRATUR, 2012; KROEFF; VERDUM, 2011). Com isso, diversos autores (COSTA; XAVIER DA SILVA, 2004; COSTA, 2006; 2008) destacam que as Unidades de Conservação têm aproveitado o seu potencial ecoturístico a fim de valorizar o ambiente natural, porém, nem sempre, o planejamento, o manejo e a gestão dessas áreas é feito de maneira adequada. A ausência de estudos de capacidade de carga de trilhas localizadas em UCs é 
alarmante. Em sua maioria, as trilhas são implementadas de forma espontânea pelos turistas e os gestores das áreas protegidas não realizam estudos adequados sobre o impacto.

Neste sentido, Neiman et al. (2009) destacam que as trilhas representam uma atração da atividade ecoturística, pois, possibilitam a aproximação dos visitantes ao ambiente natural e conduzem a um atrativo específico, estimulando o entretenimento, lazer ou educação por meio de recursos interpretativos.

Segundo Costa (2004, p.9): "as trilhas devem ser criteriosamente localizadas, planejadas, construidas e manejadas de modo a permitir a conservação dos recursos naturais e a realização de contatos adequados pelos visitantes". Porém, segundo Kroeff (2010), raramente as trilhas são planejadas e manejadas de forma adequada o que acarreta risco aos usuários e aumento dos impactos ambientais, dificultando o contato adequado do visitante com o ambiente natural.

Alguns autores (KROEFF, 2010; KROEFF; VERDUM, 2011; RANGEL; BOTELHO, 2017), destacam que o crescente número de pesquisas sobre trilhas é decorrente do impacto que elas podem causar em Unidades de Conservação (UCs) quando não manejadas adequadamente. Costa (2008) salienta que os estudos sobre o uso público em UCs tem como objetivo apresentar os tipos e as taxas de mudanças no sistema ambiental resultantes das diversas atividades existentes nessas áreas.

No ambiente de trilhas, a erosão do solo gera impactos negativos que podem afetar a experiência do usuário. Trilhas com elevados processos erosivos, acumulação de água (JEWELL; HAMMITT, 2000), ausência de estruturas de manejo eficientes e sinalização, podem gerar problemas ambientais e sociais, como a redução da atividade ecoturística, a diminuição da utilidade funcional e o desequilíbrio nos ecossistemas. Kroeff (2010, p. 2) destaca que: "dificilmente as trilhas são implantadas e manejadas de forma a propiciarem aos seus usuários o traçado mais seguro e de maior prevenção aos impactos ambientais conjuntamente com a apreciação dos melhores atributos da paisagem.".

Diversos autores (TAKAHASHI, 1998; MAGRO, 1999; COSTA, 2008; KROEFF, 2010; RANGEL et al., 2015) destacam que o pisoteio das trilhas compacta os solos alterando sua porosidade em razão da redução do volume de macroporos, o que eleva a resistência mecânica do solo, reduz a infiltração, aumenta o escoamento superficial e eleva a susceptibilidade à erosão. Além disso, Vashchenko e Biondi (2013) identificaram mudanças associadas à construção de trilhas, como compactação do solo, remoção da vegetação, modificação do padrão de drenagem existente pela remoção do topo do solo e modificação da microtopografia.

Neste sentido, é necessário destacar o impacto que a implementação e uso de trilhas, principalmente em ambientes tropicais, podem causar na qualidade do solo. A qualidade do solo é a capacidade de um solo funcionar dentro dos limites de um ecossistema natural ou manejado. É preciso manter a qualidade dos solos para sustentar a produtividade de plantas e animais. Logo, só a integração adequada das propriedades físicas, químicas e biológicas do solo que o habilita a exercer suas funções de forma eficiente (DORAN, 1997; VEZZANI; MIELNICZUK, 2009).

Pensando no impacto que a falta de planejamento e de manejo de trilhas pode causar em áreas protegidas, é preciso avaliar se a utilização das mesmas está influenciando na degradação dos solos. Neste sentido, esta pesquisa teve como objetivo analisar alguns atributos do solo, mapeando e avaliando a ocorrência de processos erosivos em duas trilhas ecoturísticas localizadas em duas Unidades de Conservação (UCs) no município de Paraty: a Reserva Ecológica da Juatinga e o Parque Nacional da Serra da Bocaina. Com isso, pretende-se sugerir medidas de recuperação de áreas degradadas e auxiliar o planejamento da atividade ecoturística subsidiando à tomada de decisão e à adoção de medidas que reduzam os impactos ambientais nas UCs.

\section{Materiais e Métodos}

\section{1 Área de Estudo}

As duas trilhas estudadas estão inseridas em duas Unidades de Conservação (UCs) localizadas no município de Paraty no litoral sul do estado do Rio de Janeiro. Essas UCs foram escolhidas por estarem inseridas na Reserva da Biosfera da Mata Atlântica, uma rede mundial de implantação de áreas protegidas, estabelecida através do Decreto Estadual 26.057/2000. Esse projeto tem como principais objetivos a manutenção da conservação do Bioma, através da implementação 
de um corredor ecológico contínuo de Mata Atlântica ao longo da costa brasileira, unindo os fragmentos florestais existentes. Além disso, integram o Corredor de Biodiversidade da Serra do Mar, pois, conjuntamente com a Área de Proteção Ambiental Cairuçu, formam um corredor ecológico.

O Parque Nacional da Serra da Bocaina (PNSB) possui área de aproximadamente 104.000 hectares, da qual cerca de 60\% localiza-se no Estado do Rio de Janeiro (municípios de Angra dos Reis e Paraty) e
40\% no Estado de São Paulo (municípios São José do Barreiro, Ubatuba e Cunha). Já a Reserva Ecológica da Juatinga (REJ) - categoria de Unidade de Conservação não contemplada pelo Sistema Nacional de Unidades de Conservação (SNUC) - está situada no município de Paraty, possui 8.000 hectares e tem como principal objetivo promover o fomento da cultura caiçara, compatibilizando seu modo de vida e a utilização dos recursos naturais com a conservação ambiental (ICMBIO, 2002) (Figura 1).

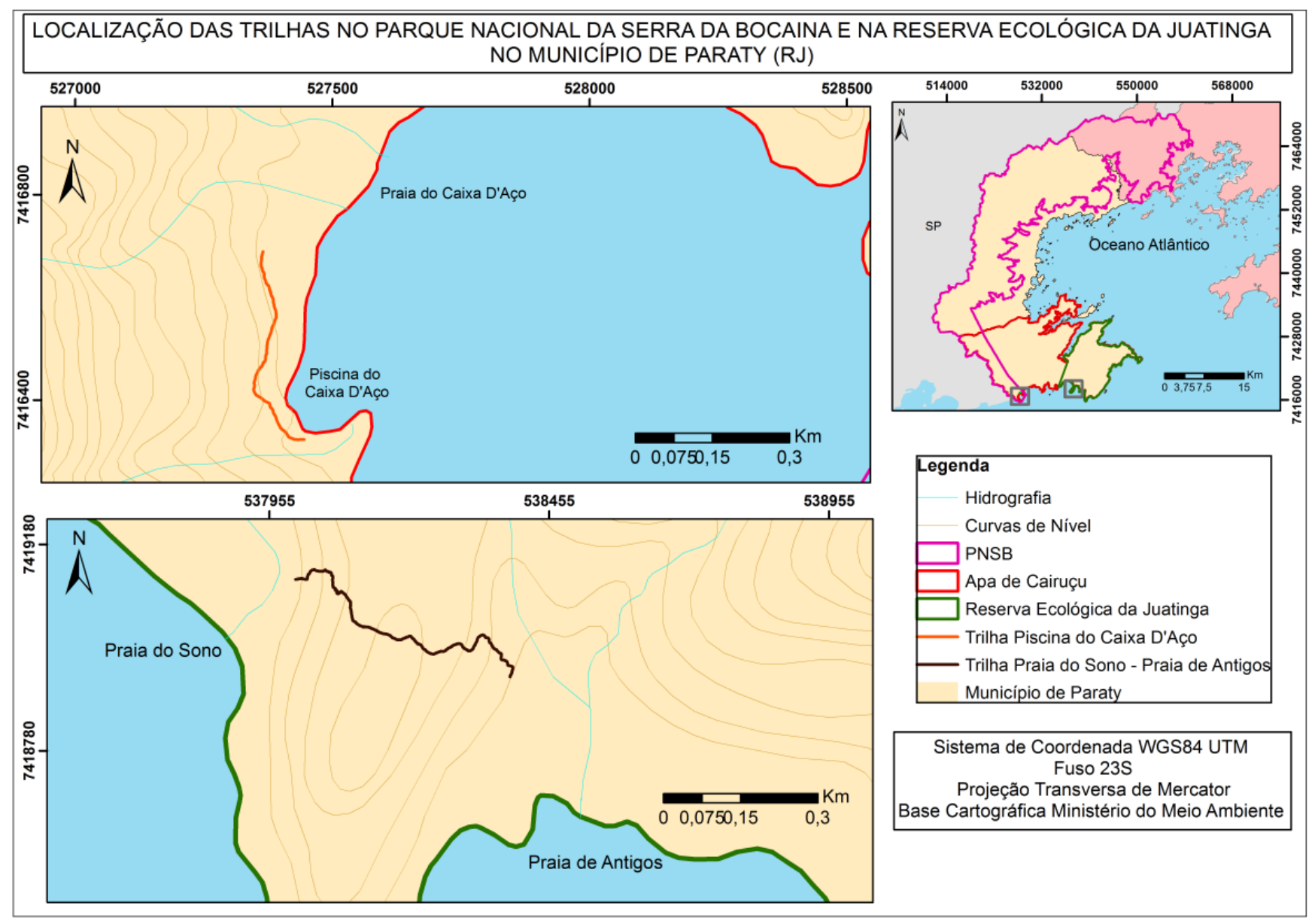

Figura 1- Localização da área de estudo. Elaboração: Rangel (2016).

O clima da região é influenciado pela compartimentação do relevo e pela variação da altimetria, que produzem descontinuidades no padrão de distribuição pluviométrica e da temperatura. Este fator reflete o efeito orográfico da Serra do Mar que atua sobre o comportamento dos sistemas frontais, principais responsáveis pela pluviosidade regional (RANGEL et al., 2015). A pluviosidade anual, no município de Paraty, varia entre $768 \mathrm{~mm}$ a $2.045 \mathrm{~mm}$, com média de 1.547 mm. Logo, a classificação climática regional é tropical úmido (ICMBIO, 2002).

Com relação às características geológicas e geomorfológicas o PNSB situa-se no Planalto da Bocaina (PONÇANO et al., 1981) e a área onde está localizada a trilha corresponde ao relevo de Montanhas e Morros. A REJ também se destaca pela topografia acidentada, caracterizada por elevadas altitudes e amplitudes das formas de relevo, derivado do contraste 
entre o domínio de escarpas e reversos da Serra do Mar com a planície costeira (GUERRA et al., 2013).

Os autores (op. cit.) ainda salientam que a geologia da área é formada, predominantemente, por associações de granitos e gnaisses do Complexo Gnáissico-Granitóide de idade proterozóica, e pela presença de sedimentos de idade cenozoica. Já os tipos de solos predominantes nas duas áreas estudadas são o Cambissolo Háplico Tb Distrófico e o LatossolosVermelho-Amarelo Distrófico nos topos e encostas mais suaves, ocupando quase toda a escarpa da Serra do Mar (ICMBIO, 2002; RANGEL et al., 2015).

A área de estudo situa-se dentro dos domínios florísticos da Zona Neotropical e agrupa a seguinte diversidade vegetacional: Floresta Ombrófila Densa (Submontana, Montana e Alto Montana), expressão dominante na região, Floresta Ombrófila Mista Alto Montana e os campos de altitude (IBGE, 1992). Segundo o ICMBio (2002), na área onde as trilhas estão localizadas há o predomínio de Floresta Ombrófila Densa secundária, em estágio médio e avançado de recuperação.

A trilha localizada no PNSB dá acesso à Piscina Natural do Caixa D'Aço, que é um sítio de geodiversidade, definido por Brilha (2016,) como um local bem delimitado onde ocorre exposição de

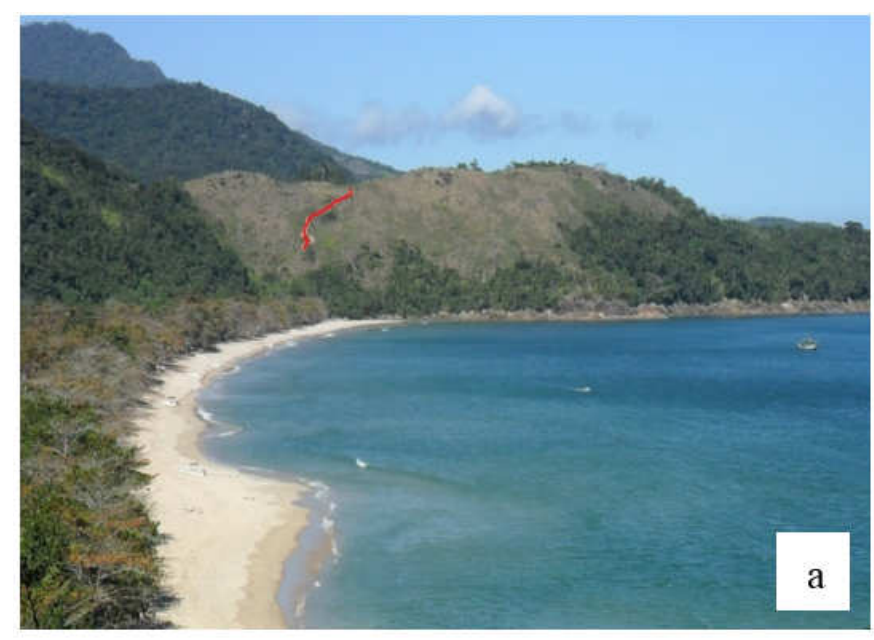

Figura 2 - (a) Vista da praia do Sono com destaque (em vermelho) para a trilha para a praia de Antigos. (b) Vista da piscina natural do Caixa D'Aço. Fotos: Luana de Almeida Rangel (2014).

\subsection{Identificação e mapeamento dos processos erosivos}

Os impactos visuais causados pela abertura da trilha e pelo uso foram analisados a partir de duas metodologias. A primeira é baseada na proposta

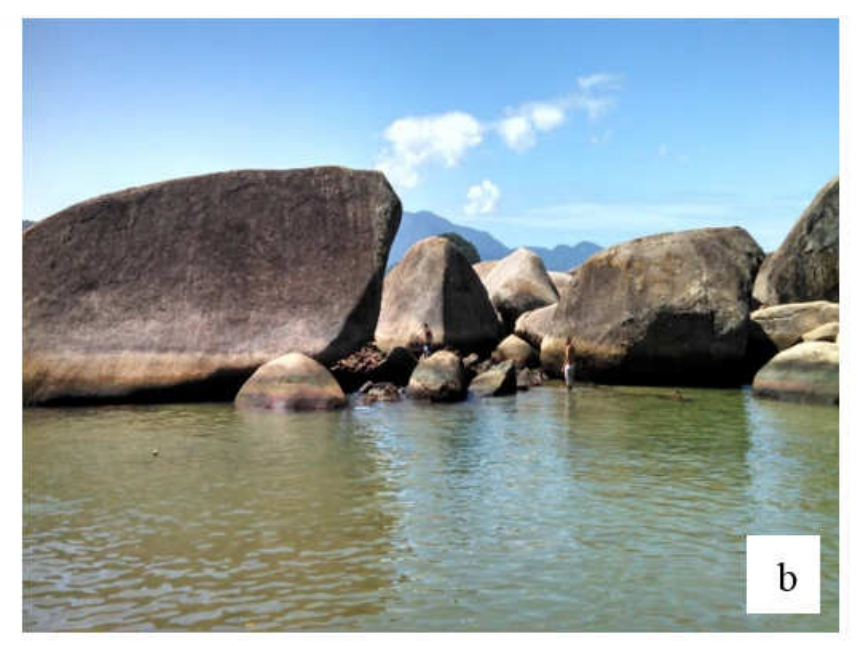

importantes materiais geológicos, geomorfológicos, paleontológicos, entre outros.

A piscina possui grande fluxo de visitantes ao longo do ano, sofrendo grande impacto da atividade turística. Segundo o ICMBio (2014) por apresentar variada fauna marinha é extremamente sensível a impactos ambientais. O acesso só é possível através da utilização de barcos que saem da praia do Meio ou pela trilha. Ela tem início no final da praia do Caixa D'Aço, próximo a diversos blocos rochosos, apesar de apresentar apenas 465 metros de extensão, possui trechos declivosos e de difícil acesso aos usuários.

Já a trilha localizada na REJ tem início na Praia do Sono, que abriga uma comunidade caiçara de aproximadamente 50 famílias, e permite acesso à Praia de Antigos que não possui nenhum tipo de construção. A trilha está localizada em uma encosta com declividade acentuada (aproximadamente $27^{\circ}$ ), evidenciando processos erosivos avançados e áreas degradadas provocadas pela concentração do fluxo de água. Ela possui extensão de aproximadamente 570 metros e a vegetação predominante é arbustiva. As duas UCs possuem grande potencial ecoturístico, principalmente na área litorânea, devido à beleza cênica, proporcionando contato com o ambiente natural (Figura 2). 
utilizada foi o Manejo de Impacto de Visitação (MIV), que prioriza o estudo dos impactos do uso da visitação visando o controle ou redução desses impactos. Partindo do princípio que todo tipo de visitação causa impacto, o MIV não busca o impacto "nulo", mas sim, o impacto em níveis aceitáveis (GRAEFE et al., 1990).

Para o mapeamento dos processos erosivos foram coletados em campo, com o GPS GARMIN 60, os pontos onde havia a presença de algum tipo de feição erosiva, como ravinas, ou pequenos movimentos de massa, e foi gerado um mapa da localização das mesmas através da utilização do software ArcGis 10 (Esri). Além disso, as feições foram ilustradas através de fotos.

\subsection{Análise das propriedades físicas e químicas do solo}

Para a realização da pesquisa foram coletadas amostras de solo em dois pontos na trilha Praia do SonoPraia de Antigos (PSA 1 e PSA 2) e dois pontos na trilha para a Piscina Natural do Caixa D'Aço (PNC3, PNC4). As amostras foram coletadas em três repetições, no leito das trilhas, ou seja, em áreas que sofrem com o pisoteio. Os intervalos de coleta foram de aproximadamente 250 metros na trilha PSA e de aproximadamente 200 metros na trilha PNC. Leung e Marion (1999) destacam que intervalos de coleta entre 100 e 600 metros são recomendados para se atingir um balanço apropriado entre acurácia e eficiência.

As coletas de amostras deformadas - para análise da granulometria, $\mathrm{pH}$, porosidade e matéria orgânica -e de amostras indeformadas - para análise da densidade do solo através do anel volumétrico - foram realizadas na profundidade de $0-10 \mathrm{~cm}$ nos meses de agosto de 2013 (trilha PSA) e maio de 2015 (trilha PNC). Essa profundidade de coleta foi escolhida, pois o solo sofre maior impacto do pisoteio nos seus primeiros centímetros, sendo possível perceber alterações nas propriedades físicas e químicas do mesmo (MADARI, 2004; DENEF; SIX, 2005). Para analisar as propriedades físicas (porosidade total, densidade do solo e textura) e químicas (matéria orgânica e pH) do solo, seguiu-se o método da EMBRAPA (2011).

A porosidade foi determinada partir da fórmula a seguir, onde $\mathrm{PT}=$ porosidade total $; \mathrm{a}=$ densidade de partículas $\left(\mathrm{g} / \mathrm{cm}^{3}\right)$ e $\mathrm{b}=$ densidade do solo $\left(\mathrm{g} / \mathrm{cm}^{3}\right)$ :
$P T=\left(\frac{a-b}{a}\right) \times 100$. Já a densidade do solo foi determinada utilizando o método do anel volumétrico (volume conhecido $\left.=100 \mathrm{~cm}^{3}\right)$ a partir da fórmula a seguir, onde $D$ representa a densidade $\left(\mathrm{g} / \mathrm{cm}^{3}\right) ; \mathrm{a}=$ massa da amostra seca a $105^{\circ} \mathrm{C}(\mathrm{g}) ; \mathrm{e} \mathrm{b}=$ volume do anel $\left(\mathrm{cm}^{3}\right): D s=a / b$. Para análise textural foi utilizado o método de análise granulométrica (dispersão total- método da pipeta), que "se baseia na velocidade de queda das partículas que compõem o solo" (EMBRAPA, 2011, p. 43).

O teor de matéria orgânica foi obtido a partir da oxidação da matéria orgânica por via úmida, com dicromato de potássio em meio sulfúrico. Já para medir o $\mathrm{pH}$ foi utilizado o medidor de $\mathrm{pH}$ (Analyser modelo $\mathrm{pH} 300 \mathrm{M}$ ), determinando o pH em água e em cloreto de potássio $(\mathrm{KCl})$. Já a classificação textural dos solos foi baseada no triângulo textural do United States Department of Agriculture (USDA, 2015) seguindo o que foi proposto por Pereira et al. (2016).

\subsection{Grau de dificuldade}

O grau de dificuldade da trilha foi analisado de acordo com o "Manual de construção e manutenção de trilhas", proposto pela Secretaria de Meio Ambiente do Estado de São Paulo (2009), no qual há divisão da trilha em trechos de acordo com sua declividade. A variação de declividade foi definida de acordo com Dias et al. (1986). Os autores classificam a trilha conforme a declividade da seguinte maneira: $0-10 \%$ - leve; 10 - 30\% - média; 30 - 50\% - difícil; 50 - 100\% - muito difícil, e $>100 \%$ - alpinismo.

Segundo Andrade (2003), a classificação do grau de dificuldade é subjetiva, pois depende da presença de desníveis de altitude, declividade, presença de processos erosivos e da qualidade topográfica do terreno. Logo, segundo o autor, o grau de dificuldade varia de pessoa para pessoa, dependendo do condicionamento físico e do peso da bagagem (mochila) carregada. Acrescentase, ainda, que ele depende da própria limitação pessoal, como, por exemplo, uma deficiência física ou visual. Além disso, a classificação do grau de dificuldade de trilhas é distinta para trilhas guiadas e trilhas autoguiadas, sendo as duas trilhas analisadas, autoguiadas.

Nas trilhas autoguiadas o grau relativo de dificuldade é determinado da seguinte forma: 1 - Caminhada leve; 2 Caminhada semipesada; 3 - 
Caminhada pesada. Nessa classificação leva-se em conta o comprimento da trilha, características do relevo, necessidade ou não de acampar, características de sinalização e a existência de mapas ou roteiros (ANDRADE, 2003).

Assim, para definir o grau de dificuldade foi utilizada, de forma adaptada, a metodologia proposta por Dias et al. (1986) e Andrade (2003), na qual foram avaliadas a declividade da rampa média e a distância a ser percorrida. A declividade foi medida ao longo das duas trilhas utilizando GPS e através da ferramenta "Perfil de Elevação" disponível no software Google Earth.

Ademais, avaliaram-se, para esta pesquisa, as características do corredor (situação do piso, presença de árvores caídas no leito da trilha e presença de vegetação no talude superior e inferior).

\subsection{Análise estatística}

Em cada ponto foram realizadas três repetições de coleta e os resultados apresentados correspondem às médias dessas repetições. Além disso, foram determinados o desvio padrão e o coeficiente de variação para melhor inferir as variações estatísticas de cada resultado. Para a realização dos testes foi utilizado o software livre Action versão 2.5 disponível no site Portal Action.

\section{Resultados e Discussão}

\subsection{Evolução dos processos erosivos}

As duas trilhas estudadas apresentaram processos erosivos já bastante evoluídos, com presença de ravinas, afundamentos no leito e erosão da borda crítica. Porém, a trilha PSA localizada na REJ está sofrendo maior degradação devido a erosão hídrica (Figura 3). Além da presença de uma ilha de vegetação no leito da trilha, que caracteriza um processo de erosão pelo efeito do pisoteio direcionado, a existência de uma voçoroca ativa de aproximadamente 1,5 metros de profundidade, indicam que os processos erosivos estão acelerados. Isso pode estar ocorrendo pela presença de vegetação arbustiva na vertente voltada para a praia do Sono, que não protege adequadamente o solo do impacto da chuva favorecendo o escoamento superficial, e também, pela elevada declividade da encosta (aproximadamente $27^{\circ}$ ).

Já na trilha PNC ficam evidentes estruturas de manejo instaladas a fim de facilitar a visitação, porém, alguns pontos com erosão da borda e estreitamento do leito representam risco para os usuários, bem como, esses trechos mais erodidos podem condicionar o caminho do fluxo de água, agravando ainda mais, os processos erosivos (Figura 4). Seabra (1999), Costa (2006), Kroeff (2010) e Rangel et al. (2015) observaram em seus estudos sobre trilhas, que a perda da borda crítica - área do lado oposto ao talude superior (COSTA, 2006) - pode ser ocasionada pela concentração do fluxo de água; pela grande presença de materiais friáveis no solo e ausência de partículas agregadoras como matéria orgânica e argila; e pelo corte inadequado par incisão da trilha, isto é, quando a mesma não acompanha as curvas de nível, sendo perpendiculares à encosta.

\subsection{Análise da qualidade físico-química do solo}

Analisando a textura do solo (Tabela 1) percebese que a classificação predominante foi a FrancoArgilosa (PSA 1 e PNC 3). A textura Franca, com elevada concentração de areia $(52,2 \%)$, encontrada no PNC 4, pode estar relacionada com a proximidade do ponto da faixa de areia.

Os solos analisados possuem altas taxas das frações areia $(43,1 \%)$, seguidos do silte $(31,1 \%)$ e da argila (25,8\%). Guerra et al. (2010) destacam que a combinação de altos teores de areia fina (>9\%), elevados teores de silte $(>20 \%)$, baixos teores de argila $(<5 \%)$ e baixos teores de matéria orgânica $(<1 \%)$, indicam alta suscetibilidade à erosão. Morgan (2005), destaca que solos com elevada presença de silte e areia fina são mais suscetíveis a processos erosivos e que solos com maiores teores de argila favorecem à agregação. Neste sentido, o PSA 1 e o PNC 3 possuem teor de silte + areia fina muito elevados $(45,6 \%$ e $45,1 \%$ respectivamente). O PNC 4 também apresenta situação crítica com relação a erodibilidade dos solos, pois possui elevado teor de areia $(52,2 \%)$ e baixo teor de argila $(17,7 \%)$. 
Rangel L. A. \& Guerra A. J. T.

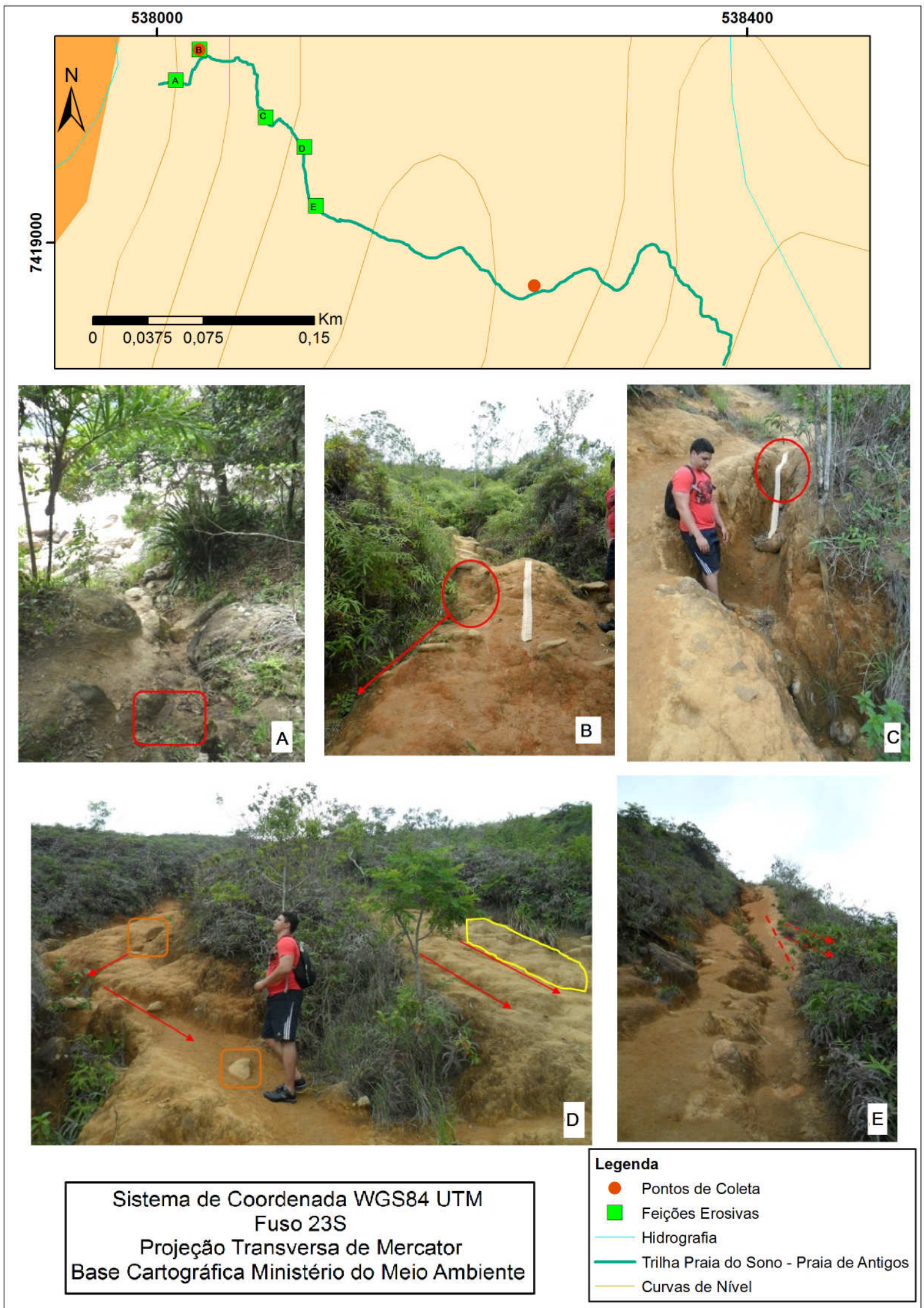

Figura 3 - Feições erosivas na trilha Praia do Sono-Praia de Antigos. (a) afundamento no leito (destaque em vermelho); (b) ravina com fluxo preferencial de água (destaque em vermelho); (c) voçoroca no leito da trilha com cabeceira evoluindo a montante (destaque em vermelho); (d) ilha de vegetação (destacado em vermelho ravinas, em amarelo degraus e alteração na microtopografia do solo, em laranja blocos rochosos); ravina em evolução e erosão da borda crítica (destaque em vermelho). Fotos: Luana de Almeida Rangel (2014). 


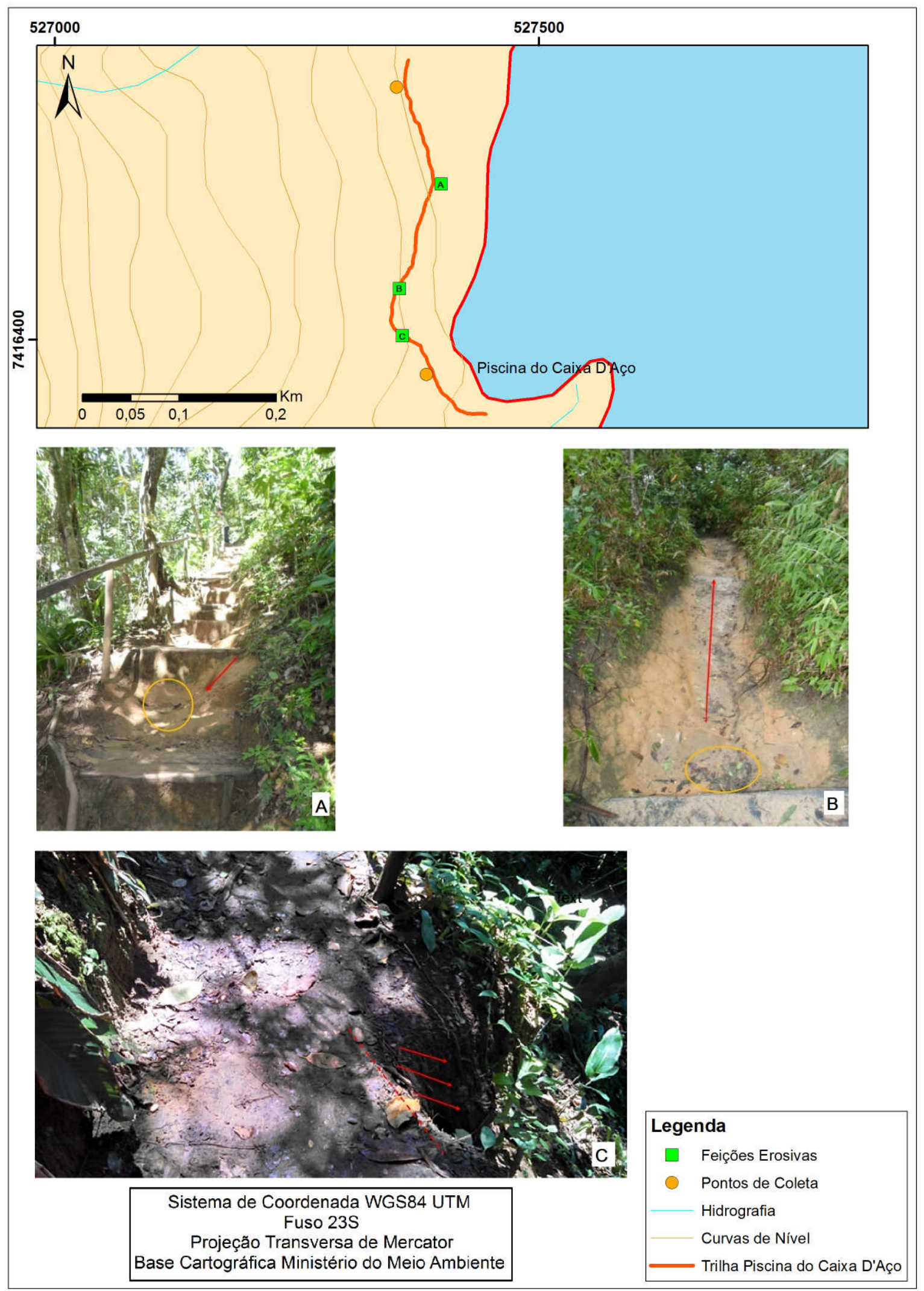

Figura 4 - Feições erosivas na trilha para a Piscina Natural do caixa D'Aço. (a) afundamento do leito (destaque em amarelo) e deposição de sedimentos na base de degraus (destaque em vermelho); (b) ravina e fluxo preferencial de água (destaque em vermelho) e acúmulo de serapilheira (destaque em amarelo); (c) erosão da borda crítica com estreitamento do leito (destaque em vermelho). Fotos: Luana de Almeida Rangel (2016). 
Com relação à porosidade Lima (2008) e Rangel e Guerra (2014) assumiram que percentuais de porosidade total acima de $45 \%$ são de baixa suscetibilidade, entre $35 \%$ e $45 \%$ são de média suscetibilidade, e menores que $35 \%$ representam alta suscetibilidade à erosão. Considerando os valores de porosidade total no solo nos pontos coletados, os resultados variaram entre médios (PSA 1, PSA 2, PNC 3) e elevados (PNC 4), em média $44,3 \%$, com 3,1 de desvio padrão e $7,1 \%$ de coeficiente de variação (Tabela 1 ).

A densidade do solo crítica é dependente de sua classe textural. Argenton et al. (2005) constataram que, em Latossolo Vermelho argiloso, a deficiência de aeração inicia-se com densidade do solo de aproximadamente $1,30 \mathrm{~g} / \mathrm{cm}^{3}$. Já Reichert et al. (2003) propuseram densidade do solo crítica para algumas classes texturais: 1,30 a $1,40 \mathrm{~g} / \mathrm{cm}^{3}$ para solos argilosos, 1,40 a $1,50 \mathrm{~g} / \mathrm{cm}^{3}$ para os franco-argilosos e de 1,70 a $1,80 \mathrm{~g} / \mathrm{cm}^{3}$ para os franco-arenosos.

Os resultados de densidade do solo (Tabela 1) apresentaram valores com média de $1,4 \mathrm{~g} / \mathrm{cm} 3$, caracterizando baixa compactação de acordo com as proposições de Fullen e Catt (2004), que consideram valores de densidade do solo média, com intervalo de 1,0 a $1,4 \mathrm{~g} / \mathrm{cm}^{3}$. Porém, seguindo os limites propostos por Reichert et al. (2013) e correlacionando os valores de densidade com as classes texturais, verifica-se que PSA 1e PNC 3 possuem densidade do solo crítica, por apresentarem textura franco-argilosa e densidades de 1,4 e $1,5 \mathrm{~g} / \mathrm{cm}^{3}$, respectivamente.

Elevados valores de densidade do solo e baixo número de poros, contribuem para menor infiltração de água da chuva, aumentando o escoamento superficial, acelerando a formação de ravinas e ocorrência de erosão laminar, removendo, assim, os minerais do topo do solo (MORGAN, 2005; RANGEL; GUERRA, 2014; PEREIRA et al., 2016). Sendo assim, esses valores podem ser associados à intensidade do pisoteio dos visitantes que compactam o solo e, consequentemente, reduzem a porosidade e o volume dos macroporos, que são responsáveis pela boa drenagem dos solos.

Os valores médios de $\mathrm{pH}$ foram de 5,7 (Tabela 1), o que segundo Brady (1989) e Lima (2008), são níveis equilibrados de $\mathrm{pH}$ (entre 5,5 e 7), representando uma faixa na qual, salvo algumas exceções, as plantas se desenvolvem de maneira adequada, nos solos de regiões úmidas. Este fato é corroborado pela presença de vegetação bem desenvolvida na área de borda da trilha.

Fullen e Catt (2004), Vezzani e Mielniczuk (2009) e Pereira et al. (2016) ressaltam que a solos ácidos estão vinculados à baixa capacidade de troca catiônica entre a vegetação e partículas do solo. Pereira et al. (2016, p. 308) afirma que "que solos com $\mathrm{pH}$ baixo interferem na fragilidade dos agregados, corroborando com a baixa permeabilidade e aeração, o que pode elevar a probabilidade de ocorrência do escoamento superficial e intensificar os problemas com a erosão acelerada", observada nas feições erosivas bem desenvolvidas ao longo das trilhas.

As análises de matéria orgânica (M.O.) permitiram inferir que a média entre os quatro pontos amostrados foi de 4,5\%. Denef et al. (2001) e Elmholt et al. (2008) destacam que a matéria orgânica do solo, viva ou morta, exerce um papel fundamental na agregação do solo. Já Franzluebbers (2002) destaca que problemas no processo de ciclagem de nutrientes podem reter a matéria orgânica na serapilheira e diminuir a quantidade de carbono para o solo.

Christensen (2001) afirma que as inter-relações entre os minerais e a interação destes com a matéria orgânica (constituindo complexos organominerais), pode afetar intensamente o tamanho dos agregados estáveis em água. Segundo Podwojewski et al. (2011) a matéria orgânica do solo desempenha diversas funções no ambiente, estando ligada a processos fundamentais como a retenção e a ciclagem de nutrientes, agregação e dinâmica da água, além de ser a fonte básica de energia para a atividade biológica. Sua perda pode interferir drasticamente nesses processos, dificultando o desempenho das funções do solo, provocando desequilíbrios no sistema e, consequentemente, desencadeando o processo de degradação.

Diante disso, Fullen e Catt (2004) afirmam que valores inferiores a 3,5\% de matéria orgânica significam instabilidade e maior suscetibilidade erosiva. Estes valores foram observados, nesta pesquisa, em PSA $1(3,1 \%)$ e PNC $3(3,3 \%)$. 
Tabela 1: Análise químicas e físicas de solo nos pontos de coleta

\begin{tabular}{|c|c|c|c|c|c|c|c|c|c|c|}
\hline \multirow{3}{*}{ UCs } & \multirow{3}{*}{$\begin{array}{l}\text { Pontos } \\
\text { de } \\
\text { coleta }\end{array}$} & \multicolumn{7}{|c|}{ Análises físicas } & \multicolumn{2}{|c|}{$\begin{array}{l}\text { Análises } \\
\text { Químicas }\end{array}$} \\
\hline & & \multicolumn{2}{|c|}{ Arranjo dos poros } & \multicolumn{5}{|c|}{ Granulometria (\%) } & \multirow[b]{2}{*}{ pH } & \multirow[b]{2}{*}{$\begin{array}{l}\text { M.O. } \\
\text { (\%) }\end{array}$} \\
\hline & & $\begin{array}{c}\text { Porosidade } \\
\text { total }(\%)\end{array}$ & $\begin{array}{l}\text { Densidade } \\
\text { aparente }(\mathrm{g} / \\
\left.\mathrm{cm}^{3}\right)\end{array}$ & $\begin{array}{c}\text { Areia } \\
\text { Fina }\end{array}$ & $\begin{array}{c}\text { Areia } \\
\text { grossa }\end{array}$ & Silte & Argila & $\begin{array}{c}\text { Classificaçãa } \\
\text { Textural }\end{array}$ & & \\
\hline \multirow{2}{*}{ REJ } & PSA 1 & 44,1 & 1,4 & 9,4 & 25,5 & 36,2 & 29,0 & $\begin{array}{l}\text { Franco } \\
\text { Argilosa }\end{array}$ & 5,6 & 3,1 \\
\hline & PSA 2 & 43,2 & 1,4 & 9,1 & 37,0 & 24,3 & 29,6 & $\begin{array}{c}\text { Franco - Argilo } \\
\text { - Arenosa }\end{array}$ & 5,7 & 5,7 \\
\hline \multirow{2}{*}{ PNSB } & PNC 3 & 41,2 & 1,5 & 11,1 & 28,2 & 34,0 & 26,7 & Fanco Argilosa & 5,6 & 3,3 \\
\hline & PNC 4 & 48,6 & 1,3 & 10,8 & 41,4 & 30,1 & 17,7 & Franca & 5,8 & 5,8 \\
\hline \multicolumn{2}{|c|}{ Média } & 44,3 & 1,4 & 10,1 & 33 & 31,1 & 25,8 & & 5,7 & 4,5 \\
\hline \multicolumn{2}{|c|}{ Desvio padrão } & 3,1 & 0,1 & 1 & 7,5 & 5,2 & 5,5 & & 0,1 & 1,5 \\
\hline \multicolumn{2}{|c|}{$\begin{array}{l}\text { Coeficiente de } \\
\text { variação (\%) }\end{array}$} & 7,1 & 5,9 & 9,9 & 22,6 & 16,7 & 21,4 & & 1,7 & 33 \\
\hline
\end{tabular}

\subsection{Análise do grau de dificuldade}

A trilha PSA pode ser subdividida, de acordo com a variação da declividade, em dois grandes trechos, o primeiro até 270 metros, correspondendo à vertente voltada para a praia do Sono, e o segundo até o final da trilha na praia de Antigos (Figura 5). Os dois trechos são bastante íngremes (aproximadamente $27^{\circ}$ no primeiro e $23^{\circ}$ no segundo), já que a trilha não é curvilínea, isto é, não acompanha as curvas de nível.

A partir desses dois grandes trechos, foram mapeados nove subtrechos com variações de declividade. O divisor da vertente está localizado no $5^{\circ}$ para o $6^{\circ}$ subtrecho, marcando, também, a mudança da vegetação na trilha. Logo, as feições erosivas estão concentradas na vertente da encosta direcionada para a praia do Sono, já que condições como orientação da mesma (NE-SO), insolação, incidência de chuvas e de massas de ar, direção do vento e presença de solos rasos são determinantes para a formação de diferentes tipos de vegetação.

Já a trilha PNC pode ser subdividida em três trechos maiores, um de aproximadamente 165 metros, o segundo trecho de 140 metros e o último de aproximadamente 160 metros (Figura 6). Os dois primeiros são marcados por declividade elevada $\left(22^{\circ}\right.$ e $18^{\circ}$, respectivamente), já o terceiro trecho é menos íngreme (aproximadamente $10^{\circ}$ de declividade).

A partir dos três trechos principais foram mapeados cinco subtrechos que indicam a variação de declividade ao longo do traçado da trilha.

A partir da observação do traçado das trilhas, verifica-se que elas não são curvilíneas. Diversos autores destacam (COSTA, 2008; KROEFF, 2010; RANGEL; GUERRA, 2014) que o traçado curvilíneo é fundamental para redução de processos erosivos e, consequentemente, redução do grau de dificuldade.

Outra questão a ser destacada é a situação do piso e a variação da qualidade do solo e da vegetação. A trilha PSA se mostra mais degradada, com declividade muito elevada, presença de feições erosivas mais desenvolvidas e ausência de estruturas de manejo que facilitem o deslocamento do visitante. A trilha PNC, apesar de possuir feições erosivas e estreitamento do leito, possui algumas estruturas de manejo e está inserida, em sua totalidade, em ambiente de floresta ombrófila, o que facilitaria o seu processo de recuperação.

Logo, de acordo com as proposições de Andrade (2003) e Dias et al. (1986), a trilha PSA pode ser considerada de grau 3, isto é, com grau de dificuldade elevado ou pesado, visto que, não há sinalização e estruturas de manejo para facilitar o deslocamento dos usuários e a declividade média da trilha é de aproximadamente $55,3 \%\left(25^{\circ}\right)$. Já a trilha PNC pode ser considerada de grau 2, isto é, com grau de dificuldade mediano ou semipesado, pois apresenta declividade média de $44,2 \%\left(20^{\circ}\right)$ e estruturas de manejo. 


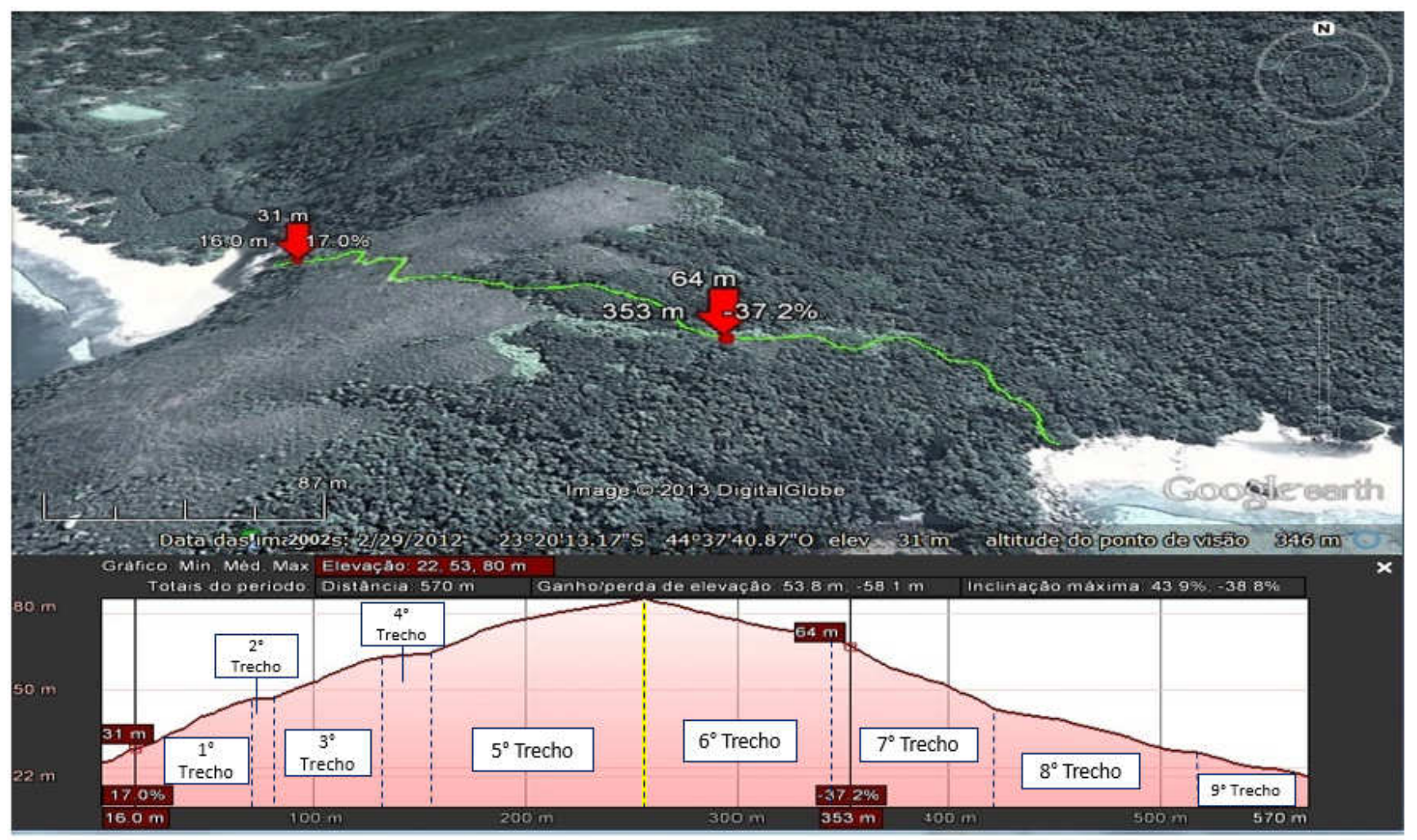

Figura 5- Perfil de elevação da trilha PSA dividido em dois trechos (linha contínua amarela) e nove subtrechos (linhas pontilhadas em azul), as setas indicam os pontos de coleta. Fonte da imagem: Google Earth (2013).

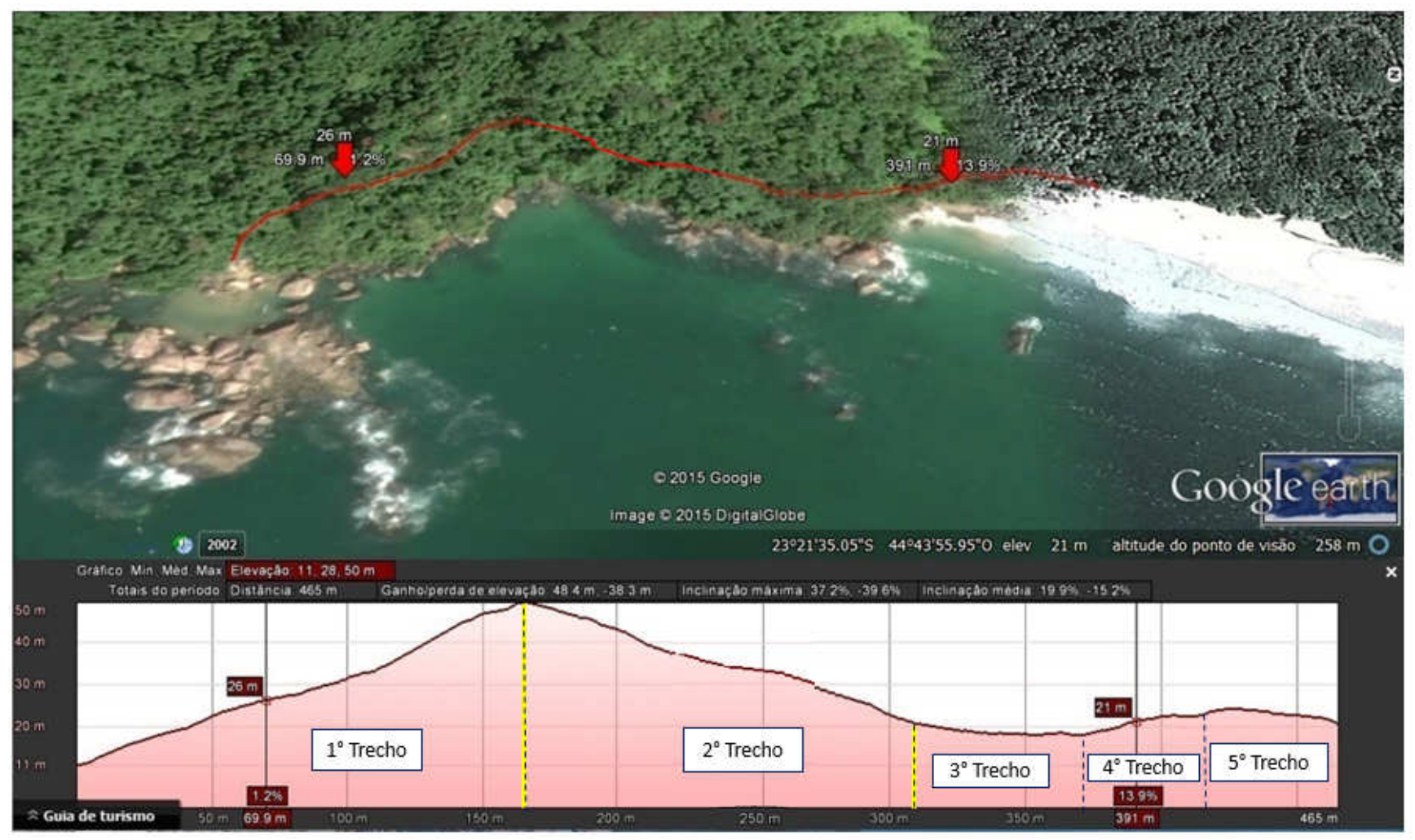

Figura 6 - Perfil de elevação da trilha PNC dividido em dois trechos (linha contínua amarela) e nove subtrechos (linhas pontilhadas em azul), as setas indicam os pontos de coleta. Google Earth (2015). 


\section{Conclusões}

A maioria das feições erosivas encontradas surgiu a partir da implementação da trilha, já que o traçado das mesmas não acompanha as curvas de nível, o que provoca diversos impactos, como a concentração do fluxo de água. Portanto, a utilização das trilhas está aumentando o escoamento superficial e aprofundando processos erosivos.

Conclui-se que está havendo dificuldade de incorporação de M.O. nas trilhas, devido a intensidade do pisoteio e ausência de vegetação. Logo, é necessário realizar estratégias - como a utilização de técnicas de bioengenharia - para recuperação da qualidade do solo.

Com relação às propriedades químicas e físicas do solo, fica evidente a correlação entre os pontos de maior degradação delimitados visualmente e os menores índices de qualidade do solo. Sendo assim, os atributos do solo avaliados se mostram eficientes para análise do grau de impacto das trilhas.

No que se refere à presença de feições erosivas, a trilha PSA apresentou feições erosivas mais desenvolvidas, sendo, portanto, a mais degradada. O elevado nível de compactação ocasionado pelo pisoteio e pela incisão é o principal responsável por convergir maior volume de água no leito trilhas, facilitando a concentração do fluxo e aprofundamento de processos erosivos.

A trilha PNC também apresentou algumas feições erosivas, porém as mesmas encontram-se menos desenvolvidas e representam menores riscos aos usuários, já que a trilha possui diversas estruturas de manejo.

Nos pontos onde foram constatadas a presença de ravinas, pode-se afirmar que o escoamento superficial é ineficiente, convergindo para o leito da trilha de forma concentrada. Sendo assim, a recuperação das áreas mais degradadas, a instalação de canaletas de drenagem e o nivelamento da trilha se tornam essenciais para a resolução do problema. Logo, com a realização dessas sugestões e dessas análises, as trilhas podem ter seu grau de dificuldade reduzido.

Conclui-se, portanto, que apesar do seu apelo ecoturístico, as trilhas, quando não planejadas e manejadas adequadamente, são forças de tensão que impactam negativamente nas condições ambientais das UCs avaliadas e na experiência do visitante.

\section{Agradecimentos}

Agradecemos à Capes, ao CNPq e à FAPERJ pelo apoio financeiro.

\section{Referências Bibliográficas}

ANDRADE, W. J. (2003). Implantação e Manejo de Trilhas. In: MITRAUD, S.W. (Org.) Manual de ecoturismo de base comunitária: ferramentas para um planejamento responsável. Brasília - WWF - Brasil - DF, p. 247-259.

ARAÚJO, G. H. de S.; ALMEIDA, J. R. de; GUERRA, A. J. T. Gestão Ambiental de Áreas Degradadas. Rio de Janeiro: Bertrand Brasil, 2013. 322p.

ARGENTON J.; ALBUQUeRQUe, J.A.; BAYER, C.; WILDNER, L.P. Comportamento de atributos relacionados com a forma da estrutura de Latossolo Vermelho sob sistemas de preparo e plantas de cobertura. Revista Brasileira de Ciência do Solo, v. 29, p. 425-435, 2005.

BERTONI, J.; LOMBARDI NETO, F. Conservação do solo. São Paulo: Ícone, 2010.

BRILHA, J. Inventory and Quantitative Assessment of Geosites and Geodiversity Sites: a Review. Geoheritage, v. 8, n. 2, p. 119-134, 2016.

CHRISTENSEN, B.T. Physical fractionation of soil and structural and functional complexity in organic matter turnover. Europe Journal Soil Science. v. 52, p. 345-353, 2001.

COSTA, N. M. C. D. e XAVIER DA SILVA, J. (2004). Geoprocessamento Aplicado à Criação de Planos de Manejo: $\mathrm{O}$ Caso do Parque Estadual da Pedra Branca - RJ. In: XAVIERDA-SILVA, J. e ZAIDAN, R. T. (Org.). Geoprocessamento e Análise Ambiental: aplicações. Rio de Janeiro: Bertrand Brasil, p.67-113.

COSTA, V. C. da. Propostas de Manejo e Planejamento Ambiental de Trilhas Ecoturísticas: Um Estudo no Maciço da Pedra Branca - Município do Rio de Janeiro (RJ). 2006. 325f. Tese (Doutorado em Geografia) - Instituto de Geociências, Universidade Federal do Rio de Janeiro, Rio de Janeiro, 2006.

COSTA, N. M. C. da. Ecoturismo: abordagens e perspectivas geográficas. In: COSTA, N. M. C. da; NEIMAN, Z.; COSTA, V. C. da. (org). Pelas trilhas do ecoturismo. Parte I. São Paulo: Ed. Rima, 2008. p.17-30.

DENEF, K.; SIX, J.; PAUSTIAN, K. e MERCKX, R. Importance of macroaggregate dynamics in controlling soil carbon stabilization: short-term effects of physical disturbance induced 
by dry-wet cycles. Soil Biology and Biochemistry, v. 33, p. 2145-2153, 2001.

DENEF, K.; SIX, J. Clay mineralogy determines the importance of biological versus abiotic processes for macroaggregate formation and stabilization. European Journal of Soil Science, Oxford, v.56, n.4, p.469-479, 2005.

DiAS, A. C.; MOURA NETTO, B. V.; MARCONDES, M. A. P. Trilha interpretativa do rio Taquaral. Boletim Técnico do Instituto Florestal. v. 40-A, p. 11-32, 1986.

DORAN, J.W. Soil quality and sustainability. In: CONGRESSO BRASILEIRO DE CIÊNCIA DO SOLO, 1997, Rio de Janeiro.

Anais... Rio de Janeiro: Sociedade Brasileira de Ciência do Solo, 1997. CD-ROM

ELMHOLT, S., SCHJØNNING, P., MUNKHOLM, L. J. e DEBOSZ, K. Soil management effects on aggregate stability and biological binding. Geoderma, v. 144, p. 455-467, 2008.

EMBRAPA. Centro Nacional de Pesquisa de Solos. Manual de métodos de análise de solo. Rio de Janeiro: EMBRAPA-CNPS. Documentos, 2011. 212p.

EMBRATUR. IEB - Instituto de Ecoturismo do Brasil. Disponível em: http://www.brasil.gov.br/turismo/2015/03/ ecoturismo-e-turismo-de-aventura-estao-em-alta-na-itb. Acesso em 12 de abril 2015.

FRANZLUEBBERS, A.J. Soil organic matter stratification ratio as an indicator of soil quality. Soil and Tillage Research., v. 66, p. 95-106, 2002.

FULLEN, M.A.; CATT, J.A. Soil Management: problems and solutions. London: Arnold, 2004.

GRAEFE, A. R.; KUSS, F. R.; VASKE, J. J. Visitor Impact management - the planning framework. Washington $D$. C. National Parks and Conservation Association, 1990.

GUADAGNIN, J. C.; BERTOL, I.; CASSOL, P. C.; AMARAL, A. J. Perdas de solo, água e nitrogênio por erosão hídrica em diferentes sistemas de manejo. Revista Brasileira de Ciência do Solo, v. 29, n. 2, p. 277-286, Viçosa, 2005.

GUERRA, A.J.T.; BEZERRA, J.F.R.; LIMA, L.D.M.; MENDONÇA, J.K.S.; GUERRA, T.T.; BUHMANN, C.; PATERSON, D.G.; PIENAAR, G.; NELL, J.P.; MULIBANA, N.E.; DEVENTER, P.W.V.; FULLEN, M.A. Land rehabilitation with the use of biological geotextiles, in two different countries. Sociedade \& Natureza, Uberlândia: EDUFU, v. 22, n 3, p. 431-446, 2010.

GUERRA, A.J.T.; BEZERRA, J. F. R.; JORGE, M. C. O.;
FULLEN, M. A. The geomorphology of Angra dos Reis and Paraty municipalities, Southern Rio de Janeiro State. Revista Geonorte, v.9, n.1, p.1-21, 2013.

IBGE, Instituto Brasileiro de Geografia e Estatística. Manual Técnico da Vegetação Brasileira. Rio de Janeiro: IBGE, 1992.

ICMBIO. Plano de Manejo do Parque Nacional da Serra da Bocaina. 2002. Disponível em: http://www.icmbio.gov.br/ parnaserradabocaina/extras/62-plano-de-manejo-e-monitorias. html. Acesso: 10 mar. 2015.

ICMBIO. Piscina natural terá limite de visitantes em Parque Nacional. 2014. Disponível em: http://www.icmbio.gov.br/ portal/comunicacao/noticias/4-destaques/4926-piscina-naturaltera-limite-de-visitantes-em-parque-nacional.html. Acesso em: 15 dez.2014.

JEWELL, M. C.; HAMMITT W. E. Assessing Soil Erosion on Trails: A Comparison of Techniques. In: USDA Forest Service Proceedings RMRS, v. 5. p. 133-140, 2000.

IRVING, M. A. (2008). Ecoturismo em áreas protegidas: da natureza ao fenômeno social. In: COSTA, N. M. C. da; NEIMAN, Z.; COSTA, V. C. da. (Org). Pelas trilhas do ecoturismo. São Paulo: Ed. Rima, 2008. p.03-15.

KIEHL, E. J. Manual de edafologia, relações solo-planta. São Paulo: Ceres, 1979.

KROEFF, L. L. Contribuição metodológica ao planejamento de trilhas ecoturísticas no Parque Nacional da Serra dos Órgãos (PARNASO), RJ. 2010. Dissertação (Mestrado em Geografia) - Instituto de Geociências, Universidade Federal do Rio de Janeiro, 2010.

KROEFF, L. L.; VERDUM, R. Identificação de áreas potenciais ao mapeamento de trilhas ecoturísticas na propriedade do Ecoparque, em Canela/RS. Revista Brasileira de Geomorfologia, v.12, n.3, p.131-136, 2011.

LEUNG, Y. e MARION, J.L. Trail degradation as influenced by environmental factors: A state-of-knowledge review. Journal of Soil and Water Conservation, v. 51, n 2, p. 130-136, 1996.

IMA, L. D. da M. Suscetibilidade à Erosão dos Solos nas Sub -bacias do médio e alto cursos da Bacia do Rio Macaé / RJ. 127 f. Dissertação (Mestrado em Geografia) - Instituto de Geociências - Universidade Federal do Rio de Janeiro, Rio de Janeiro, 2008.

MADARI, B. E. Fracionamento de Agregados: Procedimento para uma Estimativa Compartimentada do Sequestro de Carbono no Solo. Embrapa Solos: Boletim de pesquisa e Desenvolvimento. v. 22.10 p. 2004. 
MAGRO, T.C. Impactos do Uso Público em uma Trilha no Planalto Nacional do Itatiaia. Tese (Doutorado em Engenharia) - Universidade de São Paulo, São Carlos, 1999.

MAlavolta, E. Manual de Nutrição Mineral de Plantas. São Paulo: Agronômica Ceres, 2006. 638p.

MORGAN, R. P. C. Soil Erosion and Conservation. England: Blackwell, 2005.

NEIMAN, Z.; CARDOSO-LEITE, E.; PODADERA, D. S. Planejamento e implantação participativos de programas de interpretação em trilhas na "RPPN Paiol Maria", Vale do Ribeira (SP). Revista Brasileira de Ecoturismo, São Paulo, v.2, n.1, p.11-34, 2009.

PEREIRA L. S.; RODRIGUES, A. M.; JORGE, M. C. O.; GUERRA, A. J. T.; FULLEN, M. A. Processos hidro-erosivos em solos degradados em relevo de baixa declividade. Revista Brasileira de Geomorfologia (Online), São Paulo, v.17, n.2, p.299-316, 2016.

PODWOJEWSKI, P.; POULENARD, J. NGUYET, M. L.; ROUW, A.; NGUYEN, V. T.; HA PHAM, Q.; Climate and vegetation determine soil organic matter status in an alpine inner-tropical soil catena in the Fan Si Pan Mountain, Vietnam. Catena, v. 87 p. 226-239, 2011.

PONÇANO, W. L. et al. Mapa Geomorfológico do Estado de São Paulo. São Paulo: Instituto de Pesquisas Tecnológicas. 1981. 1 mapa. p. 94 .

RANGEL, L. A.; GUERRA, A. J. T. Degradação de trilhas na Reserva Ecológica da Juatinga em Paraty - Rio de Janeiro. Revista Ambiente \& Água, v.9, p.752-766, 2014.

RANGEL, L. A.; SILVA, M. A. P.; GUERRA, A. J. T. (2015) Impactos da utilização da trilha para a piscina do Caixa D'Aço no Parque Nacional da Serra da Bocaina, Paraty. In: VALEJJO, L. R.; PIMENTEL, D.; MONTEZUMA, R. C. M. (Org.) Uso público em Unidades de Conservação: planejamento, turismo, lazer, educação e impactos. Niterói: Alternativa, p. 70-82.

RANGEL, L. A.; BOTELHO, R. G. M. Análise ambiental da trilha Sahy-Rubião no Parque Estadual Cunhambebe. Revista GEO UERJ. v.30, p.391 - 418, 201.

REICHERT, J.M.; REINERT, D.J.; BRAIDA, J.A. Qualidade dos solos e sustentabilidade de sistemas agrícolas. Revista Ciência e Ambiente, v. 27, p. 29-48, 2003.

ROSS, J. L. S. Análise Empírica da Fragilidade dos Ambientes Naturais e Antropizados. Revista do Departamento de Geografia, v. 8, p. 63-74, FFLCH-USP, São Paulo, 1994.

SECRETARIA DO MEIO AMBIENTE DO ESTADO DE SÃO PAULO. Manual de Construção e Manutenção de Trilhas. São Paulo: Fundação Florestal, 2009. Disponível em: http:// www.ambiente.sp.gov.br/wp-content/uploads/publicacoes/ fundacao_florestal/ManualdasTrilhasfinal07-09.pdf. Acesso em: 22 jul. 2013.

TAKAHASHI, L. Y. Caracterização dos visitantes, suas preferências e percepções e avaliação dos impactos da visitação pública em duas unidades de conservação do Estado do Paraná. 1998. 129f. Tese (Doutorado em Engenharia Florestal) - Universidade Federal do Paraná, Curitiba.

USDA (United States Department of Agriculture). Disponível em: http://www.nrcs.usda.gov/wps/portal/nrcs/detail/soils/ survey/?cid=nrcs142p2_054167. Acesso em 05/12/2015.

VASHCHENKO, Y. Caracterização da trilha e o impacto do montanhismo nos Picos Camapuã e Tucum - Campina Grande do Sul - PR. Dissertação (Mestrado em Ciência do Solo) - Setor de Ciências Agrárias, Universidade Federal do Paraná, Curitiba, 2006.

VASHCHENKO, Y. E BIONDI, D. Percepção da erosão pelos visitantes nas trilhas do Parque Estadual do Pico Marumbi. Revista Brasileira de Ciências Agrárias. v.8, p. 108-118, 2013. VEZZANI, F. M. e MIELNICZUK, J. Uma visão sobre qualidade do solo. Revista Brasileira de Ciência Solo, v.33, p.743-755, 2009 .

WILD, A. Soils and the environment: an introduction. Cambridge: Cambridge University Press, 1993. 278p. 